\title{
AVALIAÇÃO DO ÍNDICE DE COMPACIDADE NAS SUBPREFEITURAS DO MUNICÍPIO DE SÃO PAULO
}

\author{
Assessment of the compactness index of the administrative divisions of the \\ Municipality of São Paulo
}

\author{
Rafael Barreto Castelo da $\mathrm{Cruz}^{1}$, Karin Regina de Castro Marins ${ }^{2}$ \\ Recebido em 16 de fevereiro de 2017; recebido para revisão em 20 de abril de 2017; \\ aceito em 01 de julho de 2017; disponível on-line em 28 de agosto de 2017.
}

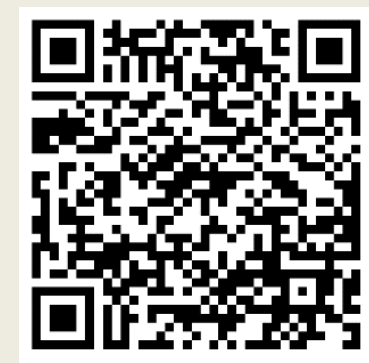

PALAVRAS CHAVE:

Índice de compacidade; Avaliação de áreas urbanas;

Cidades sustentáveis; Indicadores Urbanos; Compactação Urbana.

\section{KEYWORDS:}

Compactness index; Urban area assessment; Sustainable cities; Urban Indicators; Urban Compaction.

\begin{abstract}
RESUMO: O município de São Paulo, assim como outros municípios brasileiros populosos, tem sua urbanização marcada por forte dispersão e adensamento populacional periférico, o que gera inúmeros impactos negativos para a qualidade de vida da população, para a economia urbana como um todo e para o meio ambiente, enquanto dificulta a gestão municipal e metropolitana. Assim, a compactação surge como uma estratégia de desenvolvimento urbano, ao aproximar demandas e ofertas para maior número de cidadãos, sobretudo os menos favorecidos, agregando, dessa forma, benefícios sociais, econômicos e ambientais. A compactação da forma urbana é medida pelo seu respectivo índice, o índice de compacidade (IC), construído por uma relação métrica espacial de perímetro e área, que de forma direta, ainda relaciona às interações humanas e à organização de atividades dentro de uma área urbana. $\mathrm{O}$ objetivo do presente artigo é calcular e analisar o índice de compacidade para as subprefeituras do município de São Paulo, com pesquisa exploratória bibliográfica, mapeamento digital e aplicação matemática dos índices de compacidade. 0 estudo da compactação urbana gerou resultados significativos quando analisados comparativamente no conjunto urbano ou do município, inclusive na verificação da aplicabilidade das políticas de adensamento populacional. Entretanto, a investigação para definição de escalas intermediárias de compactação, especialmente nas médias e altas densidades, mostra-se útil para que territórios extensos e com padrões de ocupação e dinâmicas urbanas e sociais bastante distintas, possam eventualmente ser subclassificados.
\end{abstract}

ABSTRACT: The municipality of São Paulo, as well as other populous Brazilian municipalities, has its urbanization marked by strong dispersion and peripheral population density, which generates numerous negative impacts on the quality of life of the population, for the urban economy as a whole and for the environment, while hindering municipal and metropolitan management. Thus, compacting emerges as a strategy of urban development, bringing together demands and offers for a greater number of citizens, especially the less favored, thus adding social, economic and environmental benefits. The compaction of the urban form is measured by its respective index, the compactness index $(\mathrm{Cl})$, constructed by a metric relation of perimeter and area, that directly, still relates to the human interactions and the organization of activities within an urban area. The aim of this article is to calculate and analyze the compactness index for the subprefeituras of the city of São Paulo, with exploratory bibliographical research, digital mapping and mathematical application of the indices of compactness. The study of urban compaction generated significant results when analyzed comparatively in the urban or municipal set, including in the verification of the applicability of population densification policies. However, research into the definition of intermediate compaction scales, especially in medium and high densities, is useful so that extensive territories with quite distinct occupancy patterns and urban and social dynamics may eventually be subclassified

\footnotetext{
* Contato com o autor:

${ }^{1}$ e-mail: rafelcastelo@usp.br (R.B.C.Cruz)

Doutorando em Engenharia de Construção Civil e Urbana - Universidade de São Paulo, Escola Politécnica, Departamento de Engenharia de Construção Civil, São Paulo (SP), Brasil.

2e-mail: karin.marins@usp.br (K.R.C. Marins)

Professora Doutora no Departamento de Engenharia de Construção Civil - Universidade de São Paulo, Escola Politécnica, São Paulo (SP), Brasil.
} 


\section{INTRODUÇÃO}

A população urbana quintuplicou nos últimos 60 anos, saltando de 746 milhões em 1950, para 3,9 bilhões de habitantes em 2014, conforme prospecto de urbanização da ONU (UNITED NATIONS, 2015). Ainda, a tendência é de que nas próximas três décadas este número aumente, chegando a mais de 6 bilhões de habitantes em áreas urbanas em 2045.

Nesse contexto de crescimento, cidades $^{1}$ localizadas em países em desenvolvimento, tais como Índia, Brasil, África do Sul, entre outros, serão os ambientes urbanos que mais se desenvolverão, em população e extensão territorial. Assim, em 1990, havia 10 megacidades $^{2}$ no mundo, onde habitavam 153 milhões de pessoas, cerca de 7\% da população urbana, sendo apenas duas no hemisfério sul, e três em países em desenvolvimento. Em 2014, chegou-se a 28 megacidades, onde vivem 453 milhões de pessoas, cerca de $12 \%$ dos habitantes do planeta, sendo 7 dessas localizadas no hemisfério sul, com mais de uma dezena em países em desenvolvimento (UNITED NATIONS, 2015). Cidades com estas características enfrentarão desafios em atender às necessidades do crescimento e adensamento populacional. Outra característica interessante é a explosão do número de cidades com população entre 5 e 10 milhões de habitantes, as quais eram quase inexistentes (ou pouquíssimas) na década de 90 e já eram dezenas em 2014, demonstrando significativo crescimento em curto espaço de tempo.

No Brasil, o município ${ }^{3}$ de São Paulo é o mais populoso do país e a maior megacidade da América Latina e do Hemisfério Sul. São Paulo, e sua

${ }^{1}$ Cidade é o espaço de um município delimitado por um perímetro urbano (IBGE,2002)

${ }^{2}$ Megacidade é o termo para definir uma cidade que sedia uma aglomeração urbana com mais de dez milhões de habitantes com rápido processo de urbanização. (United Nations, 2015)

${ }^{3}$ Por Município, entende-se o espaço territorial político dentro de um estado ou unidade federativa, é o espaço administrado por uma prefeitura. O município possui a região metropolitana ${ }^{4}$, destacaram-se por serem a 5o maior aglomeração urbana do mundo, com aproximadamente 18,8 milhões de habitantes, conforme o mesmo relatório (UNITED NATIONS, 2015). Assim como outras metrópoles brasileiras, tem sua urbanização marcada por forte dispersão e adensamento populacional periférico, o que gera inúmeros impactos negativos para a qualidade de vida da população, para a economia urbana como um todo e para o meio ambiente, enquanto dificulta a gestão municipal e metropolitana. Assim, o adensamento populacional e construído em áreas mais centrais e acessíveis por transporte público, tornou-se uma das principais metas do último Plano Diretor de São Paulo, aprovado em 2014 (SÃO PAULO, 2014).

Assim, existem inúmeros desafios ligados ao planejamento e gestão de áreas urbanas em processo de expansão. Orientar práticas de urbanização mais sustentáveis será fundamental para formulação de estratégias onde a cidade emerja como uma construção coletiva, associando a ordem física ao atendimento de questões ambientais, sociais e econômicas. Assim, Villaça (2001) ressalta que "a estrutura territorial" também está articulada a outras não territoriais, como a econômica, a política, a ideológica e, ainda, insiste na importância de se identificar e relacionar os movimentos dos diversos elementos das estruturas territoriais urbanas - os vários bairros, o centro urbano, a estrutura de transportes, etc. - com os de outras estruturas a eles articuladas.

Portanto, é imprescindível se verificar os impactos resultantes da integração de múltiplos aspectos urbanos, de forma sinérgica e cumulativa (Adinyira et al., 2007). Nesse contexto, a "consolidação de um comparativo de indicadores"

sua zona rural e a zona urbanizada (IBGE, 2002)

${ }^{4}$ Região Metropolitana é aglomeração urbana, que se configura como metrópole estabelecida em uma unidade territorial urbana constituída pelo agrupamento de 2 (dois) ou mais Municípios limítrofes, caracterizada por complementaridade funcional e integração das dinâmicas geográficas, ambientais, políticas e socioeconômicas. 
pode "...auxiliar na avaliação das soluções urbanas baseadas em critérios e estratégias de sustentabilidade" (Marins, 2014).Segundo Braga et al. (2004), Ferreira \& Monte-Mór (2012) e Nahas (2015), os indicadores de apoio à análise de aspectos da sustentabilidade em áreas urbanas estão sujeitos a determinadas condições, entre as quais destacam-se: i. passíveis de atualizações periódicas, de tal forma que possam ser descritos em séries temporais e avaliações de seu desempenho e variações, ao longo do tempo; ii. baseados em abordagens sistêmicas diversificadas, multidisciplinares e intersetoriais; e iii. que os diversos atores e agentes que atuam na cidade, ou região, participem ativamente do processo de construção do sistema de indicadores de sustentabilidade e da sua aplicação subsequente no planejamento e na tomada de decisão política.

Segundo Wheeler (2000), Weiland (2006), Baxamusa (2008), Nahas (2015) e United Nations, (2016), o desenvolvimento urbano sustentável é ancorado no cotidiano urbano e é orientado por princípios de planejamento e gestão urbanos, tais como compacidade, diversificação, equidade social, fortalecimento da economia local e valorização de espaços públicos. Ademais, estes princípios, associados a critérios e/ou indicadores, estão sujeitos a requisitos, para que possam ser parametrizados, medidos e quantificados quanto ao seu desempenho, verificando-se se sua avaliação é sinérgica e cumulativa (Braga et al., 2004; Adinyira et al., 2007; Ferreira \& Monte-Mór, 2012; Nahas, 2015). Assim, é possível associar os princípios de desenvolvimento urbano sustentável a alguns requisitos a serem monitorados e/ou avaliados, conforme Figura1.

Como esquematizado na Figura 1 , os princípios (a) dão suporte e fundamentam a definição de critérios e indicadores de apoio à tomada de decisões em planos e projetos de desenvolvimento urbanos. Os requisitos (b), por sua vez, também são considerados na definição de critérios e indicadores, ou seja, como determinados princípios podem ser medidos, controlados e definidos. A compacidade, assim, coloca-se como um princípio a ser buscado, em oposição à dispersão urbana e sua caracterização e quantificação podem auxiliar na avaliação de áreas urbanas.

A compactação urbana é frequentemente identificada através da relação entre uma área e o número de determinados elementos; sejam pessoas, serviços, habitações ou área construída (PONT \& HAUPT, 2009.) . Ainda há outras inserções, no tocante que além da compactação urbana, a descentralização dos serviços, partindo das áreas centrais para as periferias contribui para um espaço urbano menos segregado e mais igualitário devendo haver a inclusão das áreas periféricas na cidade formal, estabelecendo a distribuição dos serviços e equipamentos urbanos, integrando centro e periferia, aponta Acselrad (2009 e 1999).

A verificação da compacidade, o primeiro

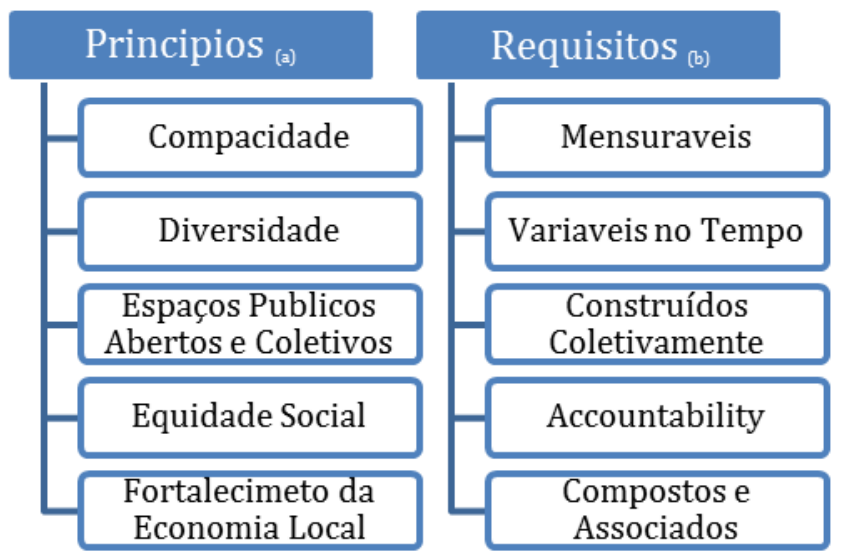

FIGURA 1: Relação entre os princípios de Urbanização Sustentável e Requisitos dos indicadores.

FONTE: Os autores (2016), baseado em: (a) Wheeler, 2000; Weiland, 2006; Baxamusa, 2008; Nahas,2015 e (b) Braga et al., 2004; Ferreira \& Monte-Mór, 2012; Nahas, 2015. 
dos cinco princípios destacados na Figura 1, em conjunto com características do uso e ocupação de solo, em um diagnóstico preliminar, pode auxiliar na análise conjunta da forma urbana e das condições de desenvolvimento econômico e social de uma área. Segundo Dempsey e Jones (2010), o Índice de Compacidade é utilizado para identificar os impactos físico-espaciais e, associado a outros indicadores, ou índices, para analisar as consequências socioeconômicas e espaciais de intervenções e a regulação das cidades em áreas ou setores administrativos.

O objetivo do presente artigo é calcular e analisar o índice de compacidade para a divisão administrativa do município de São Paulo em subprefeituras. $O$ trabalho tem caráter exploratório, baseado em revisão bibliográfica associada à análise sistematizada de imagens de satélite e demarcação de perímetros administrativos georreferenciados.

\section{COMPACTAÇÃO DE ÁREAS URBANAS E O ÍNDICE DE COMPACIDADE}

Embora não exista apenas uma forma urbana ${ }^{5}$ que se relacione com desenvolvimento urbano sustentável, para Willians et.al. (2000) é consenso que as formas urbanas com maiores densidades, com diversificação de atividades e mais compactas apresentam melhores resultados, em termos de sustentabilidade.

Lamas (2007) fornece a definição, considerando a forma urbana como sendo o "modo como se organizam os elementos morfológicos que constituem e definem o espaço urbano, relativamente à materialização dos aspectos de organização funcional e quantitativa e dos aspectos qualitativos e figurativos", que compreendem:

a) Aspectos quantitativos, tais como a densidade, as superfícies, os fluxos, os coeficientes volumétricos, dimensões,

${ }^{5}$ Maneira de descrever as características físicas de uma cidade, ou, também pode ser entendida como a configuração espacial de elementos fixos em determinada escala (Anderson, Kanargoglou e Miller, 1996). ocupações, gabaritos, perfis, de tal forma que podem ser usados para controlar e medir aspectos físicos da cidades, seu território e suas construções;

\section{b) Aspectos de organização funcional,} como os relacionados à implantação das atividades humanas no território, o uso da area em questão, ou seja, o tipo dos usos (residencial, escolar, comercial, institucional...);

c) Aspectos qualitativos, que abrangem o tratamento dado aos espaços urbanos, que podem inferir condições de qualidade, como conforto, comodidade, percepções. Podem ser analisados no meio urbano, por exemplo, pelo tipo de pavimento e a sensação que determinado elemento gera nas pessoas, ou adaptação ao clima (abrigo de chuva e vento), acessibilidade, mobilidade, etc.

d) Aspectos figurativos, que se relacionam à comunicação estética, que influi na percepção. Contudo, entende-se que, apesar de haver uma área de sobreposição entre os aspectos qualitativos e estéticos, convém distinguir que os aspectos qualitativos não são necessariamente estéticos - um ambiente com alto grau estético não implica necessariamente em boa comodidade ou conforto e vice-versa.

O modelo de cidade compacta ${ }^{6}$ depende dos processos de regulação, planejamento e gestão urbanos, quando são definidos parâmetros urbanísticos, tais como taxas de ocupação, coeficientes de aproveitamento, recuos, gabaritos, permeabilidade, uso do solo, dentre outros, os quais iram balizar os padrões de uso e ocupação do solo urbano e, assim, as condições de compacidade.

\footnotetext{
${ }^{6} \mathrm{~A}$ cidade compacta, ao contrário de uma grande cidade, sugere uma alta eficiência na organização de atividades urbanas dentro de uma área relativamente pequenaRichardson, 1973; Cole, 1964 apud (LU \& Y., 2015).
} 


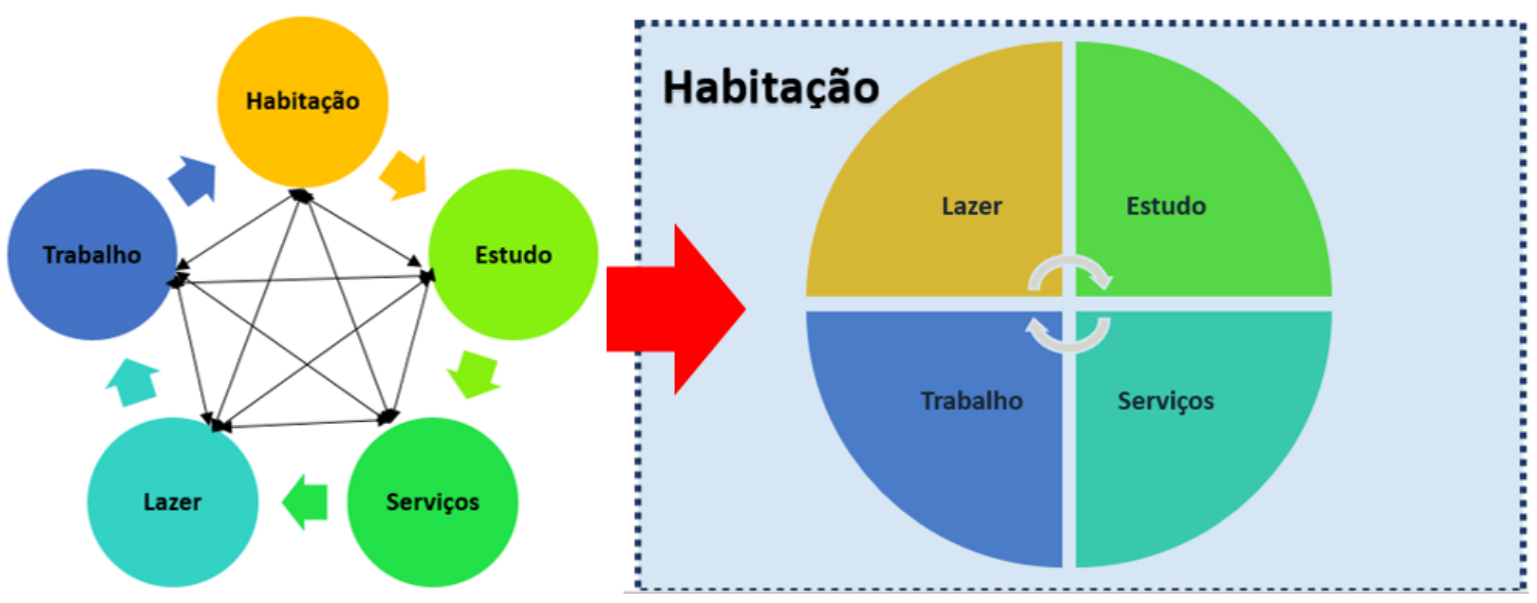

FIGURA 2: Esquema funcional da Cidade Compacta.

FONTE: Os Autores (2017), baseado em Rogers e Gumuchdjian (2001).

A cidade compacta, em um esquema funcional, sugere eficiência na organização de atividades urbanas, dentro de uma área relativamente pequena (RICHARDSON ${ }^{7}$, 1973; COLE $^{8}, 1964$ apud LU e Y, 2015). Atualmente, a aplicação do conceito de cidade compacta é, frequentemente, identificada por meio da relação entre uma área e o número de determinados elementos; sejam pessoas, serviços, habitações ou área construída (PONT e HAUPT, 2009). Segundo Acselrad (1999 e 2009), de forma aditiva, a descentralização dos serviços contribui para um espaço urbano menos segregado e mais igualitário (Figura 2), estabelecendo a distribuição dos serviços e equipamentos urbanos, integrando centro e periferia. A Figura 2, ainda, mostra sinergia e integração entre as distribuições de atividades e, nesse contexto, o modelo de cidades compactas aproxima diferentes públicos, favorece a interação e possibilita a distribuição mais equilibrada dos recursos urbanos, ao minimizar as distâncias, os deslocamentos e os custos da implementação e manutenção da infraestrutura.

Além do crescimento populacional, a expansão física e territorial também é um fator relevante no processo de desenvolvimento das cidades. Autores como Ojima (2007) apontam que

7 RICHARDSON, $H$. The Economics of Urban Size. Westmead: Saxon House, 1973.

${ }^{8}$ COLE, J. Study of Major and Minor Civil Divisions in duas aglomerações urbanas podem apresentar taxas de crescimento populacional semelhantes no mesmo período, mas uma pode configurar uma forma urbana compacta, verticalizada e monocêntrica e outra pode conformar o seu espaço urbano de modo disperso, horizontalizado e policêntrico, cada qual representando custos sociais e ambientais distintos.

As vantagens de uma cidade possuir atributos que a tornem mais compacta é um tópico que vem sendo debatido no campo do planejamento urbano e de transportes. A cidade compacta não é vista por todos como a única solução dos problemas urbanos, e seus decorrentes desdobramentos sócio econômicos e territoriais, existe uma abordagem sistêmica e mais complexa de elementos que podem trazer conjuntamente aspectos de melhor desempenho sinérgico. Cunha e Bochet (2003) referem-se à necessidade de maiores comprovações por meio de indicadores e avaliações, destacando que os argumentos a favor da densificação ainda são controversos e citam várias razões para isso: ausência de clareza na definição dos conceitos, incapacidade de definir indicadores precisos, falta de informações comparáveis, além de métodos de avaliação ainda pouco confiáveis, e ressalta-se ainda uma maior

Political Geography. The 20th International Geographical Congress. Sheffield, 1964. 
correlação com outras estratégias e esquemas funcionais.

Nesse âmbito, há métricas espaciais que representam características físicas da paisagem e da forma urbana. Segundo Li e Yeh (2004) e Lu e Y (2015), dentre estes se incluem os índices de compacidade, centralidade, densidade, porosidade, complexidade e dispersão.

Os níveis de compacidade referem-se à percepção de que, segundo Rogers e Gumuchdjian (2001), a redução das distâncias urbanas é um incentivo à caminhada ou ao uso de bicicletas, pois favorece a continuidade e a conectividade do tecido urbano, corroborando para contenção da dispersão urbana. Esta compacidade, tomada como arranjo funcional, pode dentro de uma fração territorial, geometricamente controlada, criar uma relação sinérgica entre as atividades (Trabalho, Lazer, Estudo, Serviços, Etc.) ancoradas na dinâmica habitacional.

$O$ índice de compacidade, referenciado por Lu e Y (2015), é baseado nas propostas de Cole (1964) e Richardson (1973) e resulta da Equação 1. Contudo, outra abordagem é ancorada pela proposta de Li e Yeh (2004), que aplica a Equação 2, o que, matematicamente, é análogo à Equação 1.

$$
\begin{aligned}
& I C=2 \sqrt{\pi A} / P \\
& I C=2 \pi \sqrt{\frac{A}{\pi}} /_{P}
\end{aligned}
$$

Em que:

IC = Índice de Compacidade;

$\mathbf{A}$ = área da região ema analise $\left(\mathrm{m}^{2}\right)$;

$\mathbf{P}=$ Perímetro da região em análise $(\mathrm{m})$.

Neste artigo, será empregada a Equação 1. O cálculo tem o caso circular como uma referência, que é a forma mais compacta. Onde todos os pontos mais afastados do centro são equidistantes do centro, onde a maior distância percorrida entre dois pontos será o diâmetro da superfície. $O$ índice com valor igual a 1 remete à forma circular (a mais compacta). Os valores inferiores indicam uma área menos compacta da cidade, onde A é a área urbana e $\mathrm{P}$ é o perímetro urbano. O parâmetro de classificação é proposto por Lu e Y (2015), conforme Quadro 1.

QUADRO 1: Classificação do Índice de Compacidade

\begin{tabular}{|c|c|c|}
\hline & Valor & Característica \\
\hline \multirow{3}{*}{$\begin{array}{c}\text { Índice de } \\
\text { Compacidade } \\
\text { (IC) }\end{array}$} & $\mathrm{IC}>0,50$ & Compacta \\
\cline { 2 - 3 } & $0,20<\mathrm{IC}<0,50$ & Pouco compacta \\
\cline { 2 - 3 } & $0,15<\mathrm{IC}<0,20$ & Dispersa \\
\cline { 2 - 3 } & $\mathrm{IC}<0,15$ & Muito dispersa \\
\hline
\end{tabular}

FONTE: Adaptado de Lu e Y (2015).

\section{APLICAÇÃO DO ÍNDICE DE COMPACIDADE NA AVALIAÇÃO DAS SUBPREFEITURAS DO MUNICÍPIO DE SÃO PAULO}

Como estratégia de gestão descentralizada, os municípios podem dividir o seu território em distritos, subdistritos, subprefeituras ou regionais. Essa divisão, de caráter meramente administrativo, tem por objetivo a gestão direta de alguns serviços públicos locais necessários em cada região. Um distrito pode cuidar diretamente da limpeza pública e da arrecadação local dentro de sua área, por exemplo, sem que isso represente, no entanto, uma autonomia política ou financeira em relação à Administração Municipal. (ZMITROWICZ, et.al., 2013 e ABIKO, 2011). Entretanto, em muitos casos, observa-se que está divisão administrativa torna-se uma referência territorial para a definição de políticas de interesse local, inclusive como objeto de planos e projetos de intervenção urbana específicos para cada área.

As subdivisões tornaram o quadro territorial paulistano amplo e, em grande parte, desconexo, do ponto de vista administrativo, de tal forma que cada subdivisão possui características intrínsecas, nem sempre correlatas coma 
subdivisões lindeiras, de forma sintética são quase como pequenos municípios. Segundo Sposati (2001), há enorme variação nos critérios de agregação dos "pedaços" da cidade para a organização e gerenciamento dos serviços públicos de São Paulo. Para a autora, essa multiplicidade no trato do território faz com que os cadastros territoriais não se comuniquem, dificultando a gestão pública.

De forma particular o município de São Paulo, em seu o perímetro de $365 \mathrm{~km}$ e área de aproximadamente $1.520 \mathrm{~km}^{2}$, conforme IBGE (2002), e se divide em 32 subprefeituras. Contudo, as divisões de Sapopemba e Vila Prudente são aglutinadas atualmente como uma só, formalizando então 31 divisões, conforme indicado na Figura 5.

A subprefeitura da Sé ocupa a área central do município, abrangendo distritos tais como Bela Vista, Bom Retiro, Cambuci, Consolação, Liberdade, Republica, Santa Cecilia e Sé. Perifericamente, destacam-se Parelheiros ao sul, Tremembé ao norte, e Cidade Tiradentes a leste. Sendo Parelheiros a maior delas com $360 \mathrm{~km}^{2}$, e Jabaquara a menor, com aproximadamente $15 \mathrm{Km}^{2}$, ou seja, uma variação entre a menor e a maior de 22 vezes. Todas contam com a mesma forma de gestão, processo e organização, embora suas características territoriais, áreas, usos, ocupações, perfil sócio econômico, entre outros, sejam heterogêneos.

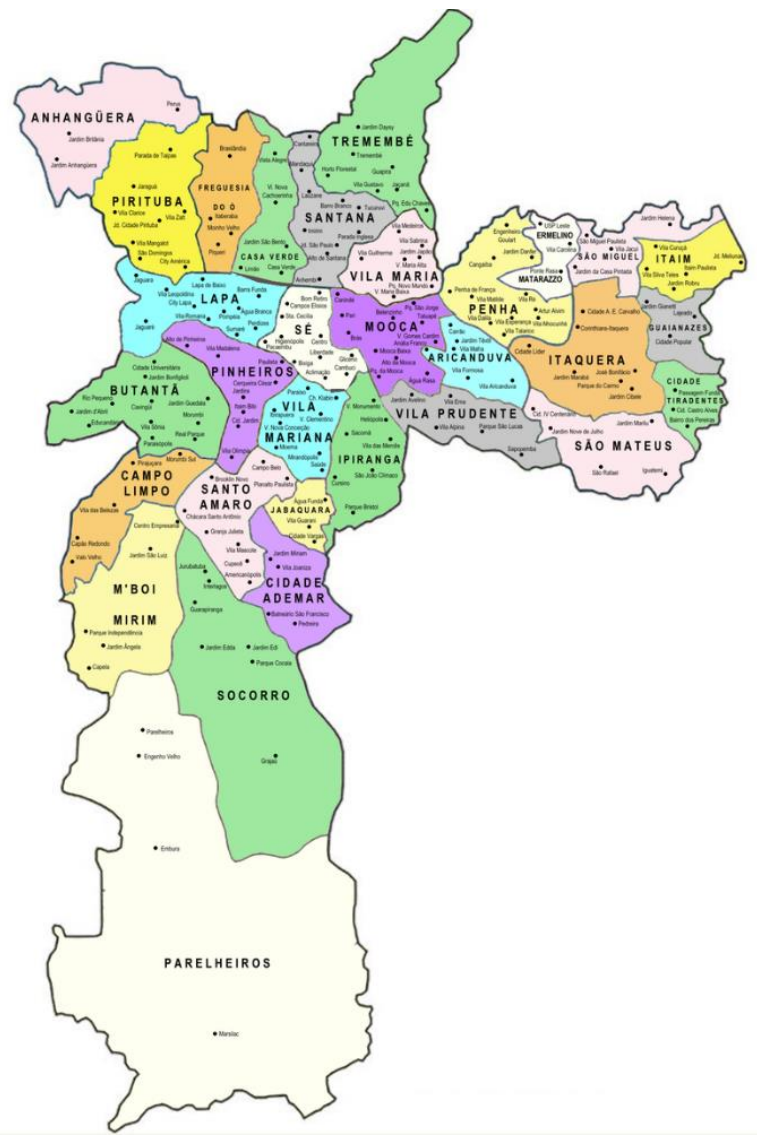

FIGURA 3: Divisão administrativa do Município de São Paulo em subprefeituras. FONTE: São Paulo (2013).

No cálculo do índice de compacidade foram utilizados dados cartográficos, obtidos através do Portal GeoSampa ${ }^{9}$ (PREFEITURA DO MUNICÍPIO DE SÃO PAULO, 2015) e imagens de satélite obtidas do INPE (Instituto Nacional de Pesquisas Espaciais, 2016), associados a dados e metodologia de classificação de área urbanas determinados pelo IBGE (Instituto Brasileiro de

9 Aplicação GeoSampa permite acesso às informações referentes ao geoprocessamento do 
Geografia e Estatística, 2015).

As informações foram integradas e analisadas como apoio do software $\operatorname{ArcGIS}^{\circledR 10}$. Com base na metodologia definida pelo IBGE para caracterização de Áreas Urbanizadas, o mapa do município de São Paulo foi georreferenciado com as imagens do Satélite CBERS-2 e foram medidos os perímetros e as áreas de cada uma das 31 subprefeituras do município de São Paulo. Contudo, os dados disponibilizados por meio da lei 13.399/2002 ${ }^{11}$ (Dispõe sobre a criação de Subprefeituras no Município de São Paulo, e dá outras providências) e da Lei 11.220/1992 ${ }^{12}$ (Institui a divisão geográfica da área do município em distritos), para a construção das superfícies, na realidade, são perímetros textuais, em resumo, constam as envoltórias determinadas por eixos viários, e não por marcos geodésicos estabelecidos na lei. Sendo assim, os dados disponíveis não são vetorizados.

Neste diapasão, os perímetros foram georreferenciados conforme marcos geodésicos oficiais da prefeitura de São Paulo, sobrepostos aos marcos do Instituto Brasileiro de Geografia e Estatística (IBGE) e inseridos nos mapas oficiais do Instituto Nacional de Pesquisas Espaciais (INPE). Por fim, foi verificado se esta sobreposição coincide com a divisão administrativa do município de São Paulo, de forma que as superfícies puderam ser vetorizadas. Por fim, foram medidos manualmente os perímetros, tanto em mapas impressos em escala quanto utilizando a ferramenta computacional ArcGIS $^{\circledR}$. Também foram calculadas as áreas das divisões administrativas, seja pelo método de Gauss, quanto com por meio da ferramenta $\operatorname{ArcGIS}^{\circledast}$.

Para cada subprefeitura do município de

${ }^{10}$ É um pacote de softwares da ESRI (Environmental Systems Research Institute) de elaboração e manipulação de informações vetoriais e matriciais para o uso e gerenciamento de bases temáticas geográficas (http://www.img.com.br/) - Versão educacional 10.5.

${ }^{11}$ São Paulo Lei 13.399/2002 - Dispõe sobre a criação de Subprefeituras no Município de São Paulo, e dá outras providências - Acesso em 15 de janeiro de 2017 -
São Paulo foram medidos seus respectivos perímetros e áreas, para, em seguida, calcular, segundo o método descrito, 0 índice de compacidade. Os resultados foram sumarizados no Quadro 3, onde nota-se que, segundo a classificação descrita no Quadro 2, todas as subprefeituras são consideradas "compactas", pois têm IC maior que 0,5, com exceção da Subprefeitura de S. Miguel, está classificada como "pouco compacta".

Verifica-se que as divisões administrativas mais periféricas e, consequentemente, mais distantes dos centros, possuem menor índice de compacidade, tais como São Miguel Paulista, Parelheiros, Perus e Guaianazes, e que as regiões historicamente melhor desenvolvidas, tais como Vila Mariana e Pinheiros, têm índices maiores que os periféricos.

Ainda, tanto uma área com IC de 0,507 quanto uma área com IC de 0,828 são, segundo a classificação do Quadro 2, consideradas compactas, o que evidentemente é uma faixa muito ampla de caracterização. Assim, a definição de faixas intermediárias de classificação parece ser necessária, para que territórios diferenciados quanto à compactação e dinâmica urbanas possam ser mais adequadamente classificados.

Por outro lado, analisando-se os índices de compacidade para outras áreas do município de São Paulo, quais sejam as operações urbanas consorciadas ou os perímetros municipais ou urbanos como um todo, como abordado por Crus e Marins (2016) e sintetizado no Quadro 3, verifica-se que em áreas que supostamente se deveria alcançar índices mais elevados, por se tratarem de áreas de incentivo ao adensamento urbano, os valores são muitas vezes semelhantes ou mesmo inferiores aos valores médios de grande parte das subprefeituras.

Disponível em: http://www.prefeitura.sp.gov.br/cidade/upload/lei_13 399 1254940922.pdf

${ }^{12}$ São Paulo. Lei 11.220/1992- Institui a divisão geográfica da area do município em distritos - Acesso - 15 de janeiro de $\quad 2017 \quad-\quad$ Disponível em: http://cmspbdoc.inf.br/iah/fulltext/leis/L11220.pdf 
QUADRO 2: Síntese dos Resultados e Classificação da Aplicação do índice de compacidade ao município de São Paulo.

\begin{tabular}{|c|c|c|c|}
\hline & Área & Índice de Compacidade (IC) & Classificação \\
\hline \multirow{2}{*}{$\begin{array}{c}\text { Município e } \\
\text { Cidade }\end{array}$} & Município de São Paulo & 0,380 & Pouco compacta \\
\cline { 2 - 4 } & Cidade de São Paulo & 0,417 & Pouco compacta \\
\hline \multirow{3}{*}{$\begin{array}{c}\text { Intervenções } \\
\text { Urbanas }\end{array}$} & OU Agua Branca & 0,675 & Compacta \\
\cline { 2 - 4 } & OUC Agua Espraiada & 0,275 & Pouco compacta \\
\cline { 2 - 4 } & OUC Faria Lima & 0,474 & Compacta \\
\hline
\end{tabular}

Fonte: Adaptado de Cruz e Marins (2016).

QUADRO 3: Síntese dos Resultados e Classificação da Aplicação do índice de compacidade as Subprefeituras do Município de São Paulo.

\begin{tabular}{|c|c|c|c|}
\hline & Subprefeitura & $\begin{array}{c}\text { Índice de } \\
\text { Compacidade (IC) }\end{array}$ & Classificação \\
\hline \multirow{31}{*}{$\begin{array}{l}\text { Verificação do } \\
\text { Índice de } \\
\text { Compacidade } \\
\text { Por } \\
\text { Subprefeitura }\end{array}$} & São Miguel & 0,452 & Pouco compacta \\
\hline & Parelheiros & 0,507 & Compacta \\
\hline & Perus & 0,532 & Compacta \\
\hline & Casa Verde/Cachoeirinha & 0,550 & Compacta \\
\hline & Campo Limpo & 0,558 & Compacta \\
\hline & Santana/Tucuruvi & 0,567 & Compacta \\
\hline & Guaianases & 0,581 & Compacta \\
\hline & Jaçanã/Tremembé & 0,584 & Compacta \\
\hline & Penha & 0,591 & Compacta \\
\hline & Lapa & 0,594 & Compacta \\
\hline & São Mateus & 0,621 & Compacta \\
\hline & Cidade Ademar & 0,624 & Compacta \\
\hline & Ermelino Matarazzo & 0,629 & Compacta \\
\hline & Butantã & 0,648 & Compacta \\
\hline & Cidade Tiradentes & 0,650 & Compacta \\
\hline & M'Boi Mirim & 0,652 & Compacta \\
\hline & Pinheiros & 0,655 & Compacta \\
\hline & Freguesia/Brasilândia & 0,655 & Compacta \\
\hline & Mooca & 0,665 & Compacta \\
\hline & Santo Amaro & 0,674 & Compacta \\
\hline & Itaquera & 0,679 & Compacta \\
\hline & Itaim Paulista & 0,679 & Compacta \\
\hline & Ipiranga & 0,683 & Compacta \\
\hline & Jabaquara & 0,685 & Compacta \\
\hline & Pirituba & 0,688 & Compacta \\
\hline & Capela do Socorro & 0,714 & Compacta \\
\hline & Aricanduva/Formosa/Carrão & 0,741 & Compacta \\
\hline & Vila Maria/Vila Guilherme & 0,750 & Compacta \\
\hline & Sé & 0,788 & Compacta \\
\hline & Vila Prudente/Sapopemba & 0,792 & Compacta \\
\hline & Vila Mariana & 0,828 & Compacta \\
\hline
\end{tabular}




\section{CONCLUSÕES}

O estudo da compactação urbana, mediante cálculo e análise do índice de compacidade, embora baseado em aspectos territoriais e político-administrativos gerais e em macroescala, gera resultados significativos quando analisados comparativamente no conjunto urbano ou do município, inclusive na verificação da aplicabilidade das políticas de adensamento populacional. Entretanto, a investigação para definição de escalas intermediárias de compactação, especialmente nas médias e altas densidades, mostra-se útil para que territórios extensos e com padrões de ocupação e dinâmicas urbanas e sociais bastante distintas, possam eventualmente ser subclassificados. Isso auxiliaria, também, na elaboração e aplicação de políticas mais adequadas às diferentes realidades urbanas. Assim, considera-se relevante proceder a um aprimoramento da categoria "compacta", definida por Lu e Y (2015), pelo menos para territórios extensos e diversificados, como é o caso do município de São Paulo.

Ainda, investigar o comportamento de outros indicadores físicos, sociais, econômicos, etc., para diagnosticar suas correlações, pode trazer contribuições relevantes em uma analise multicriterial, que não é suprida só pela consideração do índice de compacidade. Nesse âmbito, também se mostram oportunas novas pesquisas a análise de outros índices, não investigados neste trabalho, tais como centralidade, densidade, porosidade, complexidade e dispersão e sua correlação (ou relação) com a compacidade.

\section{REFERÊNCIAS BIBLIOGRÁFICAS}

ABIKO, A.K.- Texto técnico TT/PCC/10 - Serviços Públicos Urbanos. São Paulo, Epusp, 2011.

ACSELRAD, H. Duração das cidades: sustentabilidade e risco nas políticas urbanas. 2a edição. Rio de Janeiro: Ed. Lamparina, 2009, 256p.

ACSELRAD, H. Discurso da sustentabilidade urbana. Revista Brasileira de Estudos Urbanos e Regionais. Campinas, SP. Número 1, Campinas, 1999.
ANDERSON, W. P., KANARgoglou, P. S., MILleR, E. Urban Form, Energy and the Environment: A Review of Issues, Evidence and Policy. Urban Studies, v. 33, n. 1., 17-35, 1996.

ADINYRA, E.; OTENG-SEUFAH, S. \& ADJEIKUMI, T. A Review of Urban Sustainability Assessment Methodologies. International Conference on Whole Life Urban Sustainability and its Assessment M.2007

BAXAMUSA, M. The Third E: Equity as a Condition of Sustainability. Projections. Justice, Equity + Sustainability. MIT- Department of Urban Studies + Planning. Volume 8: 17-31. 2008

BRAGA, T. M.; BRITO, F.; FREITAS, A. P. \& MARQUES, D. H. F. Sustentabilidade e condições de vida em áreas urbanas: medidas e determinantes nas Regiões Metropolitanas de São Paulo e Belo Horizonte. Trabalho apresentado no XIV Encontro Nacional de Estudos Populacionais, ABEP. Caxambu - MG - Brasil, 20- 24 de Setembro de 2004: $20 p$

BRASIL. Estatuto da Cidade - Lei n. 10257, de 10 de julho de 2001. Regulamenta os arts. 182 e 183 da Constituição Federal, estabelece diretrizes gerais da política urbana e dá outras providências. Diário Oficial da União. Brasília, DF, 10 jul. 2001.

CRUZ, R.B.B., MARINS, K.R.C.C. Aplicação do Índice de Compacidade às operações urbanas consorciadas do município de São Paulo. In: XVI In: XV ENCONTRO NACIONAL DE TECNOLOGIA DO AMBIENTE CONSTRUÍDO, XVI, 201. São Paulo. Anais...São Paulo: ANTAC, 2016. p.5092 -5103.

DEAKIN, M. CURWELL, S. LOMBARDI, P. Sustainable Urban Development: The framework and directory of assessment methods. Journal of Environmental Assessment. Imperial College Press, pp.171-197, 2002.

DEMPSEY, N. E., JONES, C. Elements of Urban Form. Dimensions of the Sustainable City - Londres: Springer, pp. 21-51, 2010.

FERREIRA, V. C. \& MONTE-MÓR, R.L. M. Desenvolvimento Metropolitano e Sustentabilidade: Construção delndicadores de Sustentabilidade para uma análise da RMBH. XV Seminário Sobre Economia Mineira. Diamantina, 29-31 de agosto de 2012: 25p

GASPAR, W. Proposta metodologica de avaliação do grau de satisfação de popução em aera urbana. Estudo de Caso: bairro Antenor Garcia, municipio de São Carlos. 2007. 163p. Tese (Doutorado) - Universidade Federal de São Carlos. São Carlos, 2007.

GUJARATI, D., PORTER, D. Econometria Básica - 5.Ed. AMGH, 2011. 920p. 
INSTITUTO NACIONAL DE PESQUISAS ESPACIAIS. DGI Divisão de Geração de Imagens - Centro de Dados de Sensoriamento Remoto. São José dos Campos: INPE, 2015.

INSTITUTO BRASILEIRO DE GEOGRAFIA E ESTATISICA. Divisão Territorial Brasileira. Lima, M.H.P (org.), Rodrigues, C.M., Silva, J.K.T., Martins, P.C., Terron, S.L., Silva, R.L.S. Rio de Janeiro: IBGE, 2002. Disponível em: < http://www.ipeadata.gov.br/doc/divisaoterritorialbrasil eira_ibge.pdf>. Acesso em abr.2016.

INSTITUTO BRASILEIRO DE GEOGRAFIA E ESTATISICA. Arranjos populacionais e concentrações urbanas do Basil. Rio de Janeiro: IBGE, 2015. Disponível em: <www.ibge.gov.br/apps/arranjos_populacionais/2015>. Acesso em jan.2015.

LAMAS, J. M. Morfologia Urbana e Desenho da Cidade. 4. ed. Porto: Fundação Calouste Gulbenkian, p. 37-40. 2007.

$\mathrm{LI}, \mathrm{X} ., \mathrm{YEH}, \mathrm{A}$. Analyzing spatial restructuring of land use patterns in a fast growing region using remote sensing and GIS. Landscape Urban Planning, v.69, n.4., (October 2004) p. 335-354, 2004

LIMA, A., REIS, L., SOUSA, K. Os Planos Diretores da Grande Teresina a Gestão Ambiental Urbana: Caracterização dos Instrumentos e Politicas Locais. In: XV ENCONTRO NACIONAL DE TECNOLOGIA DO AMBIENTE CONSTRUÍDO, XV, 2014. Maceió. Anais...Maceió: ANTAC, 2014. p. 3132-314.

LU, C., Y., L. Effects of China's urban form on urban air quality Urban Studies. Urban Studies Journal Limited 2015. DOI: 10.1177/0042098015594080. China: 7 (July 2015), 1-17.2015

MARINS, K.R.C.C. Proposta metodológica para planejamento energético no desenvolvimento de areas urbanas. O potencial e soluções e morfologia e mobilidade urbanas, edifícios energia e meio ambiente: o caso da operação urbana Água Branca, no Municipio de São Paulo. São Paulo: Tese (Doutorado - Area de Concentração: Tecnologia da Arquitetura) - FAUUSP, 2010.798p.

MARINS, K.R.C.C. Comparação de estratégias e soluções de sustentabilidade aplicadas a bairros urbanos. In: XV ENCONTRO NACIONAL DE TECNOLOGIA DO AMBIENTE CONSTRUÍDO, XV, 2014. Maceió. Anais...Maceió: ANTAC, 2014. p.3179 -3188.

MEIRELLES, H.L. Direito Administrativo Brasileiro. São Paulo, Malheiros Editores, 2010.

MEIRELLES, H.L. Direito Municipal Brasileiro. São Paulo, Malheiros Editores, 2006.
NAHAS, M. I. P. \& CABANNER, Y. Indicadores de Sustentabilidade Urbana para regiões metropolitanas. In: XVI Encontro Nacional ENANPUR. Espaço, planejamento e insurgências: alternativas contemporâneas para o desenvolvimento urbano e regional, 2015. Belo Horizonte. Anais...ANPUR:20p.

OJIMA, R Dimensões da urbanização dispersa e uma proposta metodológica para estudos comparativos. Revista Brasileira de Estudos Populacionais. São Paulo, v. 24, n. n. 2, p. 277-300, jul./dez. 2007.

PONT, M. Y., HAUPT, P. Space, Density and Urban Form. Delft: TU Delft. 2009.306p.

ROGERS, R., GUMUCHDJIAN, P. Cidades para um pequeno planeta. Barcelona: Editorial Gustavo Gili. 2001.196p

ROMERO, M.A.B.A. Sustentabilidade do Ambiente Urbano da Capital. In: Brasília; Controvérsias Ambientais. Aldo Paviani e Luiz Alberto Campos Gouvêa (org). Coleção Brasília. Editora UnB, Brasília, 2003.

ROMERO, M.A.B.A. Estratégias Bioclimáticas de Reabilitação Ambiental Adaptadas ao Projeto. In Reabilitação Ambiental Sustentável Arquitetônica e Urbanística / Marta Adriana Bustos Romero, org. Brasília: FAU/UnB, 2009.

SÃO PAULO (PREFEITURA MUNICIPAL DE SÃO PAULO). LEI № 16.050, de 31 de julho de 2014 (Projeto de Lei no $688 / 13$, do Executivo, aprovado na forma de Substitutivo do Legislativo) Aprova a Política de Desenvolvimento Urbano e o Plano Diretor Estratégico do Município de São Paulo e revoga a Lei $\mathbf{n}=\mathbf{1 3 . 4 3 0 / 2 0 0 2}$. Diário Oficial do Município de São Paulo. 2013.

SANTOS, M. Manual de Geografia Urbana. São Paulo: Huicitec.1989.225p

SPOSATI, A., 2001. A cidade em pedaços. São Paulo: Editora Brasiliense.

UNITED NATIONS. World Urbanization Prospects: The 2015 Revision. New York: UN, 2015.

VILLAÇA, F. (2001). Espaço intra-urbano no Brasil. São Paulo: Studio Nobel: FAPESP: Lincoln Institute.

WEILAND, U.Sustainability Indicators and Sustainable Development. In: Wuyi, W., Krafft, T., Kraas, F.: Global Change, Urbanization and Health. China Meteorological Press, Beijing, pp. $241-250.2006$

WHEELER, S. M. 2000. Planning for metropolitan sustainability. Journal of Planning Education and Research, Association of Collegiate Schools of Planning 20: 133-145. 
WILLIANS, K., BURTON, E., JENKS, M. Achieving

Sustainable Urban Form. Londres. E \& FN. 2000. 408p.

ZMITROWICZ, W., BISCARO, C., MARINS, K.R.C.C.

TT/PCC/20 A Organização Administrativa do Município e o Orçamento Municipal - 37p.2013. 